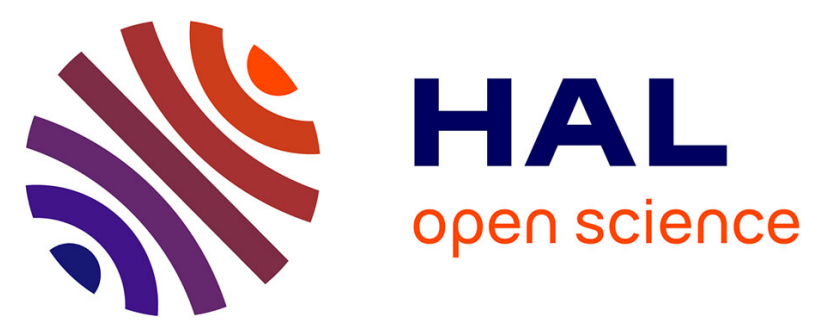

\title{
Decay extent assessment of small-diameter silver fir logs degraded in natural conditions in the French Northern Alps using NIRS and vibration resonance methods
}

\author{
Jean-Baptiste Barre, Franck Bourrier, David Bertrand, Marie-France \\ Thévenon, Freddy Rey
}

\section{To cite this version:}

Jean-Baptiste Barre, Franck Bourrier, David Bertrand, Marie-France Thévenon, Freddy Rey. Decay extent assessment of small-diameter silver fir logs degraded in natural conditions in the French Northern Alps using NIRS and vibration resonance methods. Ecological Engineering, 2017, 109 (Part B), pp.240-248. 10.1016/j.ecoleng.2017.06.002 . hal-01824006

\author{
HAL Id: hal-01824006 \\ https://hal.science/hal-01824006
}

Submitted on 14 Sep 2021

HAL is a multi-disciplinary open access archive for the deposit and dissemination of scientific research documents, whether they are published or not. The documents may come from teaching and research institutions in France or abroad, or from public or private research centers.
L'archive ouverte pluridisciplinaire HAL, est destinée au dépôt et à la diffusion de documents scientifiques de niveau recherche, publiés ou non, émanant des établissements d'enseignement et de recherche français ou étrangers, des laboratoires publics ou privés. 


\title{
Decay extent assessment of small-diameter silver fir logs degraded in natural conditions in the French Northern Alps using NIRS and vibration resonance methods
}

\author{
J.B. Barré ${ }^{\mathrm{a}, *}$, F. Bourrier ${ }^{\mathrm{a}}$, D. Bertrand ${ }^{\mathrm{c}}$, M.F. Thévenon ${ }^{\mathrm{b}}$, F. Rey $^{\mathrm{a}}$ \\ a Université Grenoble Alpes, Irstea, UR EMGR, 2 rue de la Papeterie-BP 76, F-38402 St-Martin-d'Hères, France \\ ${ }^{\mathrm{b}}$ CIRAD, UR BioWooEB, TA B 114/16, 34398 Montpellier Cedex 5, France \\ ${ }^{\mathrm{c}}$ INSA Lyon (National Institute of Applied Sciences of Lyon), Université de Lyon, 20, Avenue Albert Einstein, Villeurbanne Cedex, France
}

Bioengineering structures devoted to natural hazard mitigation often require the implementation of veg-etation and inert materials, mainly timber logs. The latter are intended to ensure the protective function of the structure until the crop development of the plants is sufficient. The structural use of raw wood, i.e. without wood preservative treatment, in severe decay conditions is specific to the bioengineering structures. It raises practical and scientific issues regarding wood-decay assessment for structure man-agement as well as for studies related to design improvements. In this study, two methods assessing the level of decay - the near infra-red spectroscopy (NIRS) method and the vibration resonance method (VRM) - developed on logs degraded in semi-controlled conditions were applied and compared. These methods are based on a mechanical definition of the level of decay by means of the normalized loss in the modulus of elasticity between intact and decayed states. The level of decay of 60 small-diameter silver fir logs degraded in natural conditions in the French Northern Alps was assessed using both methods. The samples had been put on the ground in four different sites near alpine torrents. The degradation process was assumed to take place in aerobic conditions. Prior to assessment of the level of decay, the applicability of the methods was verified. The level of decay was based on a classification varying from class 1 for the least decayed logs to class 4 . Both methods allowed assessing the effects of the microbial activity on the logs. The levels of decay found were mainly classes 1 and 2 in both cases but to various extents depending on the method. Finally, the NIRS method was found to be less reliable than VRM. VRM can be used to assess the level of decay of logs decayed in natural conditions.

\section{Introduction}

One of the multiple objectives of ecological engineering, viewed as the design of projects using and/or acting for nature (Rey, 2017), is the mitigation of natural hazards such as shallow landslides (Mao et al., 2012) and soil erosion (Rey, 2009). As ecological engineering solutions, bioengineering structures are composed of a living part made of plants. An inert part is usually added so that plants can reach maturity and resist constraints and forces imposed by the environment (Tardo and Mickovski, 2016), often involving a timber log assembly made of local species (Zeh, 2007). Developing these bioengineering structures takes advantage of wood's biodegradability (Kail et al., 2007). Nevertheless, the current lack

\footnotetext{
* Corresponding author.

E-mail address: jean-baptiste.barre@irstea.fr (J.B. Barré).
}

of knowledge slows down the prescription of this kind of structure. One of the main points which has been highlighted by practitioners is the assessment of the state of structures over time and the logs' level of decay, in particular because logs are subjected to wood decomposers.

Wood decomposition is the consequence of the action of the saproxylic community, composed of insects and their larvae, and the microbial community (Stokland et al., 2012). Decay is a particular type of wood decomposition resulting from microbial activity (Zabel and Morrell, 1992). In this context, microbial activity mainly stems from fungal or bacterial activity depending on the aerobic conditions. Fungi decay wood in aerobic conditions while bacteria require anaerobic conditions. For bioengineering structures, wood, in contact with the ground and not immersed, is not saturated in water and provides appropriate aerobic conditions for fungal growth (Noetzli et al., 2008). In these conditions, fungi depolymerize wood's chemical compounds (lignin, cellulose and 
hemicellulose) and break the wood down at the microscopic and macroscopic scales. This in particular reduces the mechanical properties, including the modulus of elasticity (MOE) (Wilcox, 1978). Based on the changes in wood properties, methods have been developed to assess wood's level of decay (Zabel and Morrell, 1992).

The level of decay of wood has been widely investigated to predict the residual service life of structures. In the context of bioengineering structures, the assessment of the level of decay always includes a visual inspection of the entire structure and of each log, as may be done on other timber structures (Feio and Machado, 2015). The visual inspection consists of identifying and localizing the most damaged parts as indicated by changes in color and appearance. The practitioner may also complete the visual inspection by fungus identification (Noetzli et al., 2008; Rickli and Graf, 2014) and a residual (not decayed) log cross-section evaluation. The visual investigation is quantitative and is based mostly on the practitioner's experience. Therefore, the visual investigation is generally coupled with semi-destructive techniques (SDTs) (Noetzli et al., 2008; Rickli and Graf, 2014; Akita, 2015) or non-destructive techniques (NDTs) (Kasal and Tannert, 2011) to quantitatively assess the remaining wood properties. Amongst SDTs, resistance drilling is a common technique that measures the energy needed for drilling (Rinn et al., 1996).

Resistance drilling can detect changes in density and is suited for bioengineering structure investigation (Ceraldi et al., 2001). However, resistance drilling is local and does not provide information on the wood's mechanical properties. Amongst NDTs in the context of bioengineering structures, Romano et al. (2016) studied decay assessment by means of ultrasonic tomography, which consists of measuring the transit time of an ultrasonic wave through the wood sample. However, they did not find any evident and robust correlation between NDTs and standard static bending tests measuring mechanical properties. Previati et al. (2012) monitored levels of log decay using their water content measured by time domain reflectometry, which is usually used to study the soil's water content. However, the measurements have not been compared with the mechanical properties of decayed logs.

Recently, an SDT and an NDT method were developed by Barré (2017) to assess the level of decay of small-diameter silver fir (Abies alba) logs degraded in semi-controlled conditions. First, Barré (2017) used a near infra-red spectroscopy (NIRS)-based method to assess the level of decay. This SDT method is based on a prediction model of a reference indicator $D w_{M O E}$ using post-treated spectra. $D w_{M O E}$ was defined as the normalized loss in MOE of logs measured using a static bending test between intact and decayed states. $D w_{M O E}$ ranges from 0 to 1 . Secondly, Barré (2017) proposed an indicator $D w_{E_{n}}$ calculated from measurements obtained by the vibration resonance method(VRM). The VRM can measure the dynamic modulus of elasticity (DMOE), which is sensitive to the effects of wood decay, and a quantity of interest for the design of structures (CEN, 2005). The authors obtained a $R^{2}=0.84$ coefficient of determination between the assessment with $D w_{E_{n}}$ and $D w_{M O E}$.

The two methods are differentiated in particular by their investigation scales. A NIRS-based method assesses decay at a local scale from cores sampled on the log, whereas the VRM is considered a global-scale method because it assesses decay for the entire log. Both methods were developed with a degradation process taking place in a greenhouse to improve the decay kinetics. These semi-controlled conditions may have influenced the microbial community composition and its development with potential effects on the level of decay (van der Wal et al., 2015) and the nature of degraded compounds (Zabel and Morrell, 1992). The extent of decay in logs might also be influenced by the logs' layout in the greenhouse given that they were buried under a 5-cm layer of soil. Furthermore, the soil type has a great influence on the level of decay (Brischke and Rapp, 2008), especially because the water-holding capacity varies between soil types (Rahman and Chattopadhyay, 2007). The aim of this study was to assess the level of decay of small-diameter silver fir logs degraded in natural conditions using the NIRS-based method and the VRM developed by Barré (2017) in semi-controlled conditions. First, it was necessary to check the applicability of the methods on logs degraded in natural conditions, i.e. in contact with the ground near alpine torrents. The applicability of the methods was checked by observing the decay in the log's cross-section, the moisture content and the effects of microbial activity on lignin and cellulose. Secondly, this study aimed to compare the levels of decay of silver fir logs assessed using each of the two methods. The levels of decay determined by the two methods were first analysed independently and then converted into decay classes in order to facilitate their comparison.

\section{Materials and methods}

\subsection{Samples preparation and experimental sites}

Sixty small-diameter logs of silver fir (A. alba) were harvested in a silver fir forest located in Lagarde-en-Oisans (France: $45^{\circ} 3^{\prime} 51.84^{\prime \prime} \mathrm{N}, 6^{\circ} 3^{\prime} 34.26^{\prime \prime} \mathrm{E}$ ) at $1300 \mathrm{~m}$ above sea level, in the French Northern Alps. They were $160 \mathrm{~cm}$ in length with a mean diameter comprised between 6 and $10 \mathrm{~cm}$. Particular attention was paid to ensure that the three types of geometrical imperfections of logs (curvature, tapering and roundness of the cross section) were below the maxima recommended by Barré (2017). The logs were then uniformly spread between four experimental sites located in the Grésivaudan valley (Isère - France) and were left in the field for 659 days from June 2014 to April 2016.

In the Grésivaudan valley, the climate is oceanic with continental influences. At an altitude of $220 \mathrm{~m}$, the mean annual precipitation is $934 \mathrm{~mm}$ and the mean annual temperature ranges from $6.3^{\circ} \mathrm{C}$ in winter to $16.2^{\circ} \mathrm{C}$ in summer (Météo-France, 1981-2010). The four sites were chosen for their proximity (from $2 \mathrm{~m}$ to $20 \mathrm{~m}$ ) to torrents in Bresson, Ecorchiers and La Terrasse, where civil or ecological engineering torrent control check dams had previously been built. Elevation, exposure and the presence or absence of forest canopy were the other field characteristics taken into account (Table 1). On each site, 15 small-diameter logs were laid on the ground. These experimental conditions correspond to the use class 4 use according to EN 335 (CEN, 2013). In these

Table 1

Main characteristics of experimental sites.

\begin{tabular}{|c|c|c|c|c|c|}
\hline Site & Commune & Altitude & Coordinates & Orientation & Description \\
\hline Bresson & Sainte-Marie-du-Mont & $1100 \mathrm{~m}$ & $\begin{array}{l}45^{\circ} 22^{\prime} 52.94^{\prime \prime} N \\
5^{\circ} 55^{\prime} 0.75^{\prime \prime} E\end{array}$ & East & $\begin{array}{l}\text { Moderately forested area } \\
10 \mathrm{~m} \text { from the torrent }\end{array}$ \\
\hline La Terrasse & La-Terrasse & $340 \mathrm{~m}$ & $\begin{array}{l}45^{\circ} 19^{\prime} 56.42^{\prime \prime} N \\
5^{\circ} 55^{\prime} 17.57^{\prime \prime} E\end{array}$ & Southeast & $\begin{array}{l}\text { Heavily forested area } \\
1 \mathrm{~m} \text { from the torrent }\end{array}$ \\
\hline Ecorchiers "Bas" & Saint-Ismier & $530 \mathrm{~m}$ & $\begin{array}{l}45^{\circ} 15^{\prime} 42.11^{\prime \prime} N \\
5^{\circ} 49^{\prime} 23.72^{\prime \prime} E\end{array}$ & Southeast & $\begin{array}{l}\text { Sparsely forested area } \\
1 \mathrm{~m} \text { from the torrent }\end{array}$ \\
\hline Ecorchiers “Haut” & Saint-Ismier & $610 \mathrm{~m}$ & $\begin{array}{l}45^{\circ} 15^{\prime} 49.88^{\prime \prime} N \\
5^{\circ} 49^{\prime} 18.33^{\prime \prime} E\end{array}$ & Southeast & $\begin{array}{l}\text { Sparsely forested area } \\
10 \mathrm{~m} \text { from the torrent }\end{array}$ \\
\hline
\end{tabular}


(a)

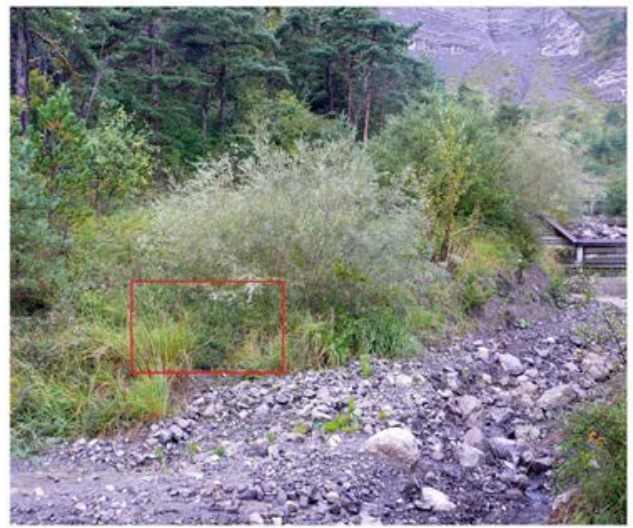

(c)

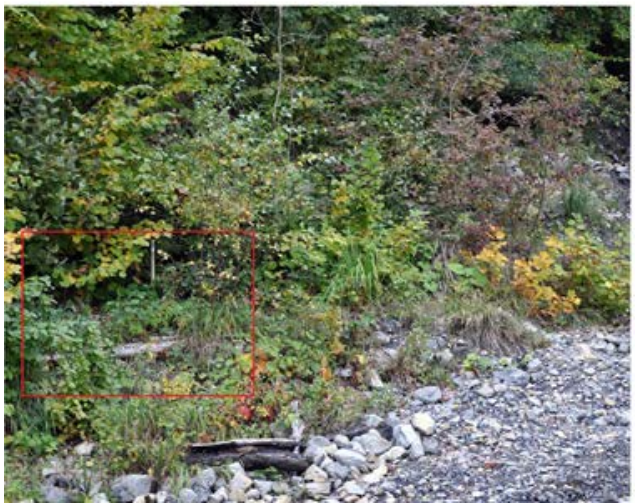

(b)

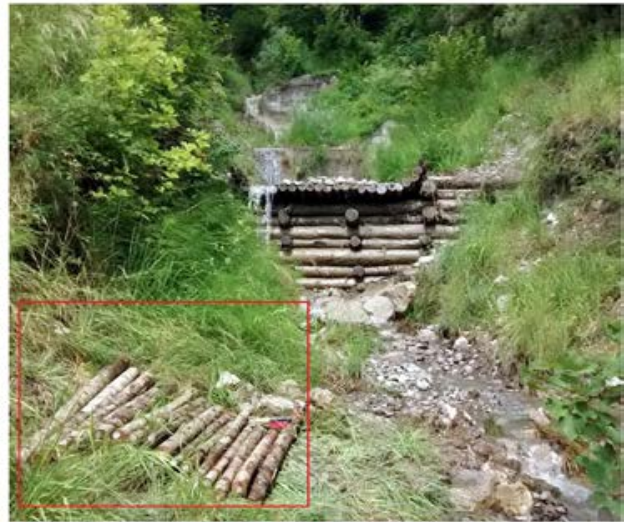

(d)

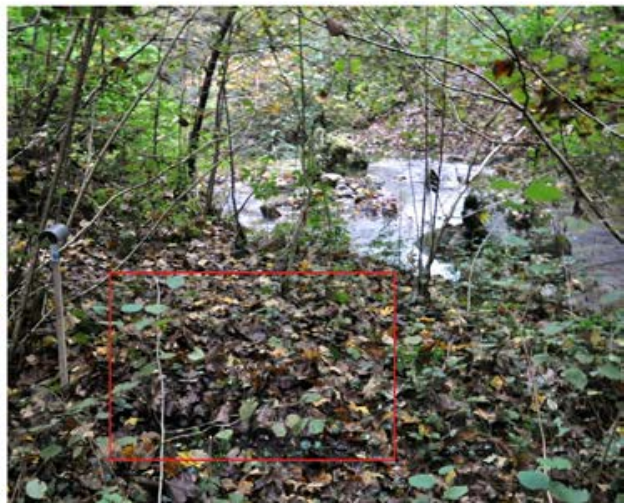

Fig. 1. Experimental sites: (a) Ecorchiers "Haut" torrent, (b) Ecorchiers "Bas" torrent, (c) Bresson torrent, and (d) La Terrasse torrent.

conditions, the standard states that the average moisture content throughout the year should exceed $20 \%$. The log-diameter distribution was similar between sites. Soils are located on calcareous and marly-calcareous substratums. For the Ecorchiers and Bresson sites, the soils had a coarse texture without litter (Fig. 1a-c). For La Terrasse site, the soil had a fine texture and a litter layer (Fig. 1d).

\subsection{Applicability of the methods on samples degraded in natural conditions}

Samples in natural conditions may be degraded in a way that is not compatible with the applicability of the methods as they have been developed with samples degraded in semi-controlled conditions. Therefore, particular attention was paid to the extent of decay in the cross section, the moisture content at the time of investigation and the effects of the microbial activity on cellulose and lignin in the NIRS spectra investigation.

\subsubsection{Observations using visual inspection of the logs cross-sections.}

The microbial activity changes the visual aspect of wood, most particularly its colour and its texture. Visual inspection is an efficient method to identify decay areas in a qualitative manner. Bark limits the visual investigation to the cross section of decayed logs. Cross sections were investigated at the macroscopic scale following the recommendations of Zabel and Morrell (1992) and Schmidt and Czeschlik (2006). The absence or presence of the three types of decay was enumerated after fine sandpapering: (i) changes in normal wood colour patterns going from bleached to dark brown spots may occur with soft or brown rot, (ii) black demarcation lines (zone lines) appear frequently with white rot, although this may occur with brown rot (Maloy and Murray, 2001), (iii) blue discolorations stem from blue stain fungi that have no effect on the mechanical properties.

\subsubsection{Moisture content of logs}

The NIRS and VRM methods were developed with samples, whose Moisture Content (MC) was above the Fibre Saturation Point (FSP). This condition is important because the MC has huge effects on wood properties, most particularly mechanical properties. Moreover, as water is one of the main drivers of fungus development (Brischke and Rapp, 2008), the MC of decayed samples reveals relevant indications on the degradation conditions.

After the degradation period, a $5-\mathrm{cm}$ slice of $5 \mathrm{~cm}$ was sampled on each log for the MC measurement. The MC was calculated according to Eq. (1) and the recommendations of Williamson and Wiemann (2010). The oven-dry weight $\left(W_{0}\right)$ was measured after sample drying until weight stabilization using a Memmert oven set at $103.5^{\circ} \mathrm{C}$

$M C=\left[\frac{\left(W_{h}-W_{0}\right)}{W_{0}}\right] \times 100$

where $W_{h}$ is the wet weight.

The MC results between sites were compared using the Student's $t$-test.

\subsubsection{Effects of microbial activity on cellulose and lignin using NIRS}

NIRS measures the reflectance of samples subjected to light radiation whose wavelengths vary from 1000 to $2500 \mathrm{~nm}$ $\left(10,000-4000 \mathrm{~cm}^{-1}\right.$ in wavenumbers). The absorbance $(A)$ of 
the samples is calculated from the reflectance $(R)$ according to $A=\log (1 / R)$ (Chalmers and Griffiths, 2002). The vibration of the chemical functional groups induced by light is the origin of the absorbance and depends on the wavelengths. The excitation by light of the functional groups generates vibrations of their chemical bonds.

Prior to the spectrum acquisition, each debarked sample was transversely drilled to obtain shavings that were ground into a powder with a $0.25 \mathrm{~mm}$ grain size in a Retsch ZM 200 mill. This operation homogenized the properties of the cross-section, which may be spatially heterogeneous due to fungal activity. A measurement done only on the surface of the sample could lead to false evaluation. An alternative would be to perform several measurements on a core sample taken from the log. Samples were then dried at $40^{\circ} \mathrm{C}$. NIR spectra were acquired by a Thermo Scientific Antaris 2 FT-NIR analyser. The instrument records the absorbance in the spectral region [3999, 10,001 $\mathrm{cm}^{-1}$ ] at a resolution of $4 \mathrm{~cm}^{-1}$. Each spectrum is the average of 32 scans and is plotted as absorbance versus wavenumbers. The Savitzky-Golay second derivative associated with a 11-point smoothing filter(Savitzky and Golay, 1964; Rinnan et al., 2009) was used to analyse the spectra with respect to others studies that commonly applied this pre-processing method to emphasize peaks positions and separations (Chalmers and Griffiths, 2002, volume 3 ). The peaks positions may be indirectly assigned to wood compounds (Schwanninger et al., 2011) and changes in their amplitudes reflect changes in compounds contents. In particular, NIR spectra provide information that can be used to investigate the effects of fungal activity on wood (Fackler and Schwanninger, 2012) by means of wavelengths assignments in NIR spectra (Schwanninger et al., 2011). Various studies confirmed that the effects of the microbial activity on wood may be analysed by means of changes in the peaks amplitudes. Thus, changes in peaks amplitude assigned to lignin have been observed by Fackler et al. (2007a,b) and Schwanninger et al. (2004), near $5980 \mathrm{~cm}^{-1}$ for samples exposed to white rot. For polysaccharides, scattered changes were noted along the full spectral range. Variations due to decay have been observed by Sandak et al. (2013) for cellulose at $4280 \mathrm{~cm}^{-1}, 4404 \mathrm{~cm}^{-1}, 4620-4890 \mathrm{~cm}^{-1}$ and $5464 \mathrm{~cm}^{-1}$.

\subsection{Comparison of the level of decay assessed by the NIRS based method and the VRM}

\subsubsection{Assessment of the level of decay using the NIRS based method.}

The NIRS based method developed by Barré (2017) assesses the level of decay of a silver fir sample by means of its NIR spectrum and a model of prediction of the indicator $D w_{M O E}$. For this purpose, the authors developed a model to predict the normalized loss of MOE $D w_{M O E}$ of silver fir small-diameter logs from spectra using partial least square regression (PLSR). Data processing and model developments were carried out with R software (R Core Team, 2013) and the HyperSpec package (Beleites and Sergo, 2012).

The method proposed by Barré (2017) is based on the calculation of a differential spectrum defined as the difference between a mean intact spectrum obtained from 125 intact silver fir samples and the baseline corrected spectrum of the decayed sample. The mean intact spectrum is an average of 125 spectra of silver fir cores collected from different locations in the French Northern Alps. The model was calibrated from 72 decayed small-diameter logs from the same location as the logs studied herein. The logs were degraded over periods ranging from 5 to 26 months under semi-controlled conditions in a greenhouse (located near Grenoble, France). The model took into account spectra within a limited range of wavenumbers: $4258-4304 \mathrm{~cm}^{-1}, 4350-4404 \mathrm{~cm}^{-1}$ and $4570-4674 \mathrm{~cm}^{-1}$. The model was validated with 31 independent samples from the same location. The coefficient of determination

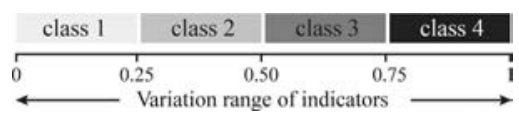

Fig. 2. Equivalence rule between the indicators $D w_{N I R S}$ or $D w_{E_{1}}$ and the four classes of decay.

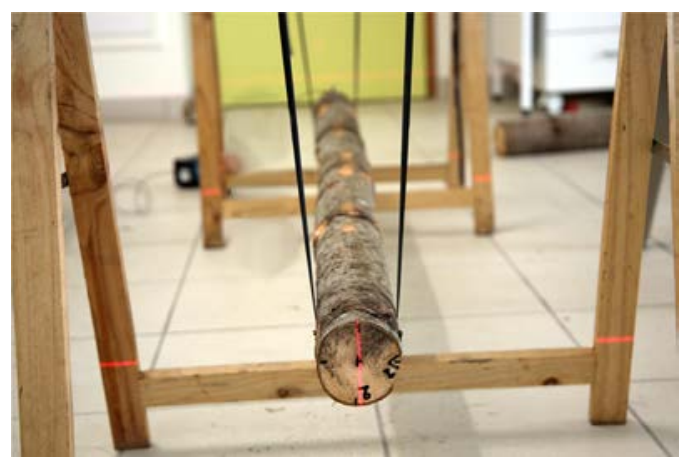

Fig. 3. Test bench for the MOE measurement.

between measured and predicted values $\left(R_{p}^{2}\right)$ was 0.77 and, the root mean square of prediction (RMSEP) 0.13. The level of decay assessed by the NIRS-based method was named $D w_{\text {NIRS }}$ (Fig. 4). To facilitate the comparison with VRM and attenuate differences between the indicators $D w_{N I R S}$ and $D w_{E_{1}}$, notably those due to the difference in examination scales, the level of decay based on indicators was converted into classes. The decay class was assigned to each sample using the equivalence rule detailed in Fig. 2.

\subsubsection{Assessment of the level of decay using the vibration resonance method}

The VRM was initially designed to measure the MOE in dynamic conditions. It is based on the Euler-Bernoulli theory and calculates the DMOE of a beam in free vibrations from its natural frequency (Brancheriau and Bailleres, 2002). The VRM measures the DMOE of intact and decayed logs using a specific test bench. The supports of the test bench were made of rubber bands that ensure boundary conditions equivalent to a free-free supported beam (Fig. 3). Barré (2017) detailed the methodology that was reproduced in this study. The vibrations were initiated by a vertical impulse at one extremity and recorded at the other by a Deltraton type 4397 piezoelectric accelerometer from Brüel \& Kjær. The accelerometer was powered by Deltraton Power Supply WB 1372 and its signal converted by the PicoScope 4224 analogue-to-digital converter from Pico Technology. The Fast Fourier transform (FFT) of the digital signal was calculated to determine the vibration modes using $R$ software $(R$ Core Team, 2013) and the Signal package (Signal developers, 2014). Since the geometrical imperfections of logs were similar to those of logs used by Barré (2017), the first mode of vibration was taken into account; otherwise, the second mode would need to be considered, which is less sensitive to geometrical imperfections. Thus, the DMOE, called $E_{n}$, was calculated next for the first mode according to the Euler-Bernoulli theory (Eq. (2)).

$E_{1}=4 \pi^{2} M L^{3} \frac{f_{1}^{2}}{I X_{1}}$

with $E_{1}$ the MOE calculated for the first mode of vibration, $I$ the moment of inertia, $M$ the sample mass, $L$ the beam length, $f_{1}$ the fundamental frequency and $X_{1}=500.5467$.

The indicator $D w_{E_{1}}$ was calculated from one measurement at the intact state and one from the decayed state (Fig. 4). $D w_{E_{1}}$ corresponds to the normalized loss in $E_{1}$ between the intact and decayed 


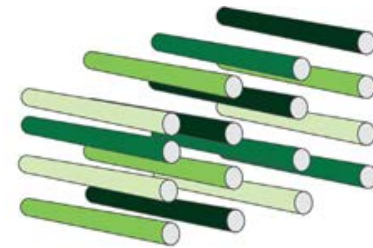

60 intact silver fir logs Mean Diameter: $80 \mathrm{~mm}$ Length : $1550 \mathrm{~mm}$

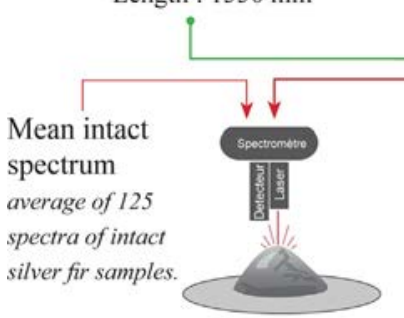

NIRS based method developed by Barré (2017)

Indicator Dw $w_{\text {NIRS }}$

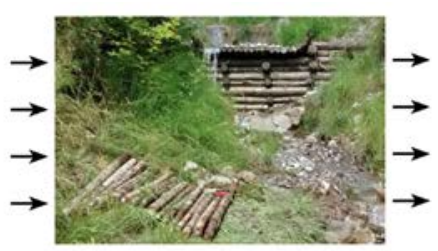

4 experimental sites

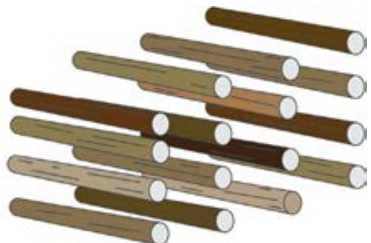

60 decayed silver fir logs

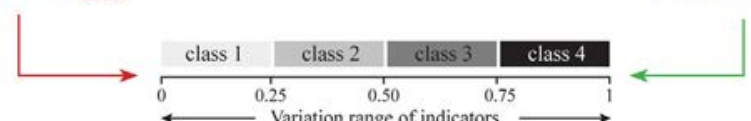

Fig. 4. Synthesis of the methodology using the two methods and their associated indicators.

(a)

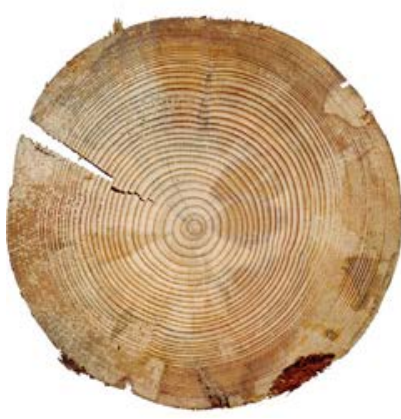

(b)

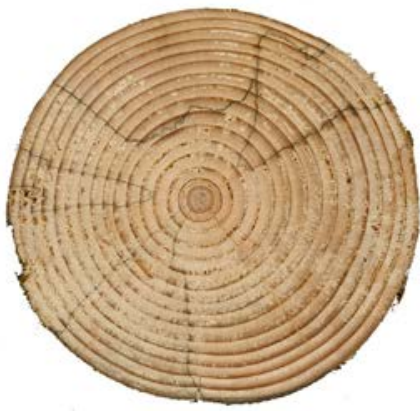

(c)

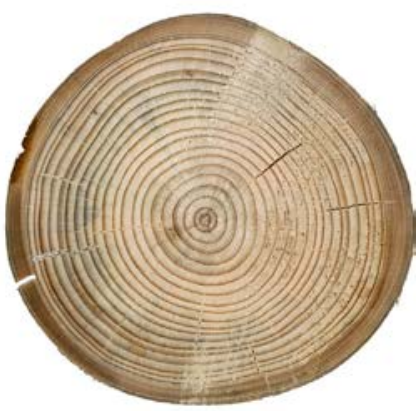

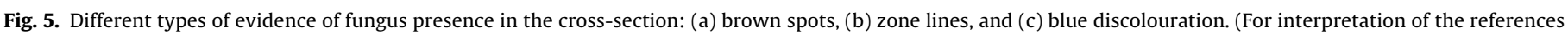
to color in this figure legend, the reader is referred to the web version of the article.)

states (Eq. (3)). The decay classes based on $D w_{E_{1}}$ were obtained with the same rule as those based on $D w_{\text {NIRS }}$ (Fig. 2)

$D w_{E_{1}}=\frac{E_{1}^{i}-E_{1}^{d}}{E_{1}^{i}}$

with $E_{1}^{i}$ the MOE calculated for the first mode of vibration at the intact state, and $E_{1}^{d}$ at decayed state.

\subsubsection{Comparison of methods using the means of classes.}

The degradation classes obtained from the two methods were finally compared using a confusion matrix calculated with the Caret package (Kuhn, 2016).

\section{Results}

3.1. Applicability of the methods on samples degraded in natural conditions

\subsubsection{Observations using visual inspection of the logs} cross-sections

Silver fir heartwood is considered as slightly durable (Durability class 4) towards fungi, sapwood being always considered as non durable (CEN, 2016). No significant distinction between sapwood and heartwood was visually observed. The first visual evidence of decay was the black demarcation lines (Fig. 5a), which were present on all sites for all samples at Ecorchiers Bas and Bresson (Fig. 6), to a lesser extent at La Terrasse and for only five samples in Ecorchiers Haut. The presence of brown discolouration (Fig. 5b) was relatively rare and was especially observed in Ecorchiers Haut and La Terrasse (four samples). About one-third of the samples had blue discolouration (Fig. 5c), asserting the presence of blue stain fungi. At all sites, 


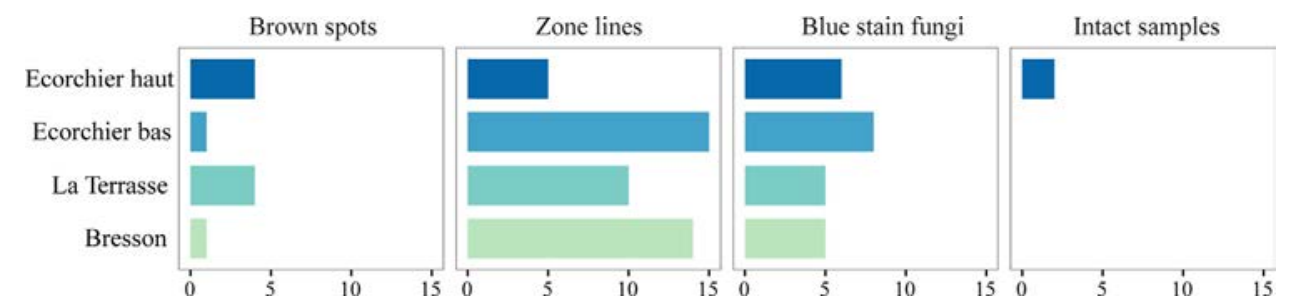

Fig. 6. Visual inspection according to the experimental sites. Figures represent the number of logs.

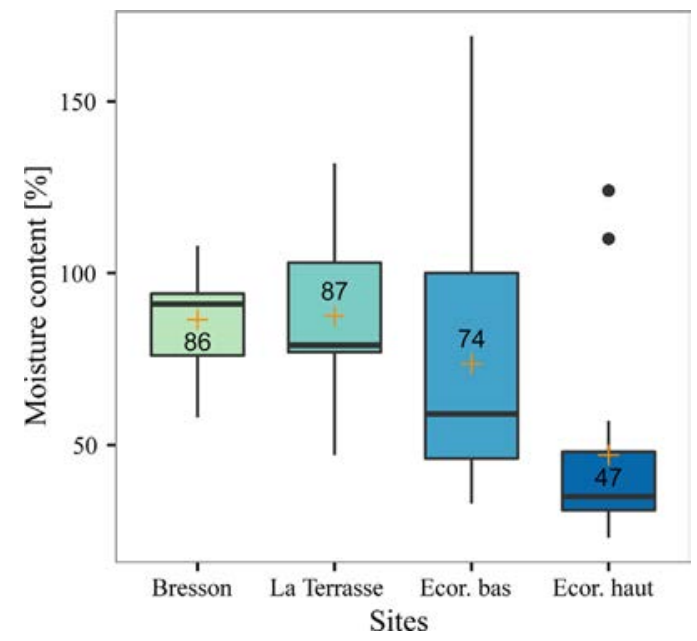

Fig. 7. Moisture content of the logs at the end of the experiment for the experimental sites. Crosses correspond to mean values.

three samples showed galleries of wood-boring beetles. Finally, two samples showed no evidence of decay. In all cases, cracks had resulted from drying shrinkage during storage since no crack was observed on the wet cross section soon after the on-site sampling.

\subsubsection{Moisture content of logs}

The MC was above the FSP for all samples except for three of them belonging to Ecorchiers Haut site (Fig. 7). The measurements highlighted the Ecorchiers Haut site whose MC was significantly lower than those of the other sites. The MC at Bresson and La Terrasse was quite similar (mean, $86 \%$ and $87 \%$, respectively). The mean MC of Ecorchiers Bas was lower (74\%) but its standard deviation (36\%) was higher than for first two sites, respectively (13\% and $24 \%$ ). The Ecorchiers Haut logs had the lowest mean MC (47\%). It was significantly lower than the MC of the other sites according to the Student t-test between Ecorchiers Haut and Ecorchiers Bas's MC $(p$-value $=0.030)$.

\subsubsection{Effects of microbial activity on cellulose and lignin using NIRS}

The spectrogram shows decreases in the amplitude of spectra of decayed samples compared to those of intact samples. The decreases were pronounced for some spectral bands where the separation of the ribbons, i.e. the SD of both groups of spectra, is observed were separated. For example, a dissociation of the ribbons may be observed near $4400 \mathrm{~cm}^{-1}$ (Fig. 8) or $5980 \mathrm{~cm}^{-1}$ (Fig. 9). Furthermore, the dissociation of the ribbons was generally associated with peaks of the lignin spectrum. For bands assigned only to the cellulose, the difference between both the two groups of spectra was not so as pronounced, such as near $6300 \mathrm{~cm}^{-1}$ (Fig. 9) or near $4365 \mathrm{~cm}^{-1}$ (Fig. 8).

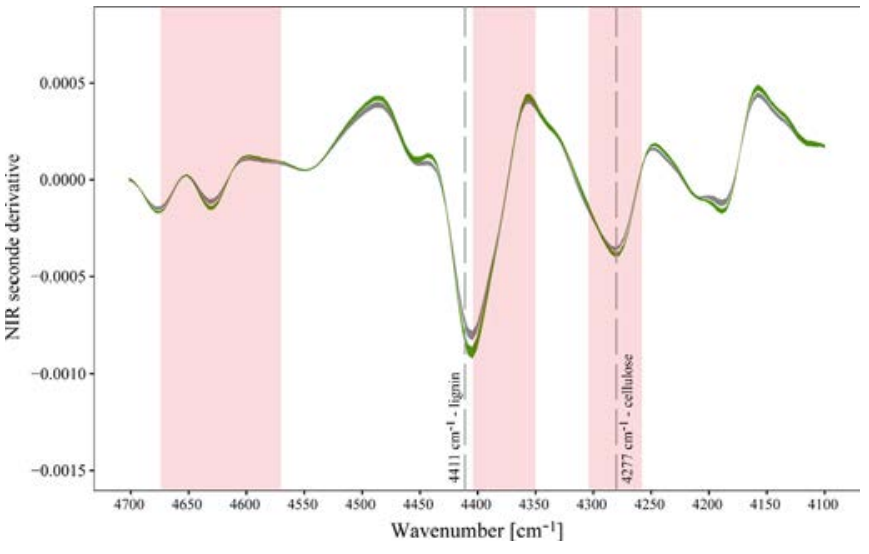

Fig. 8. SD of the second derivative spectra of intact samples (green) and decayed samples (grey). Spectral range: $4700-4100 \mathrm{~cm}^{-1}$. The red ribbons indicate the spectral ranges taken into account in the prediction model of the NIRS based method. (For interpretation of the references to color in this figure legend, the reader is referred to the web version of the article.)

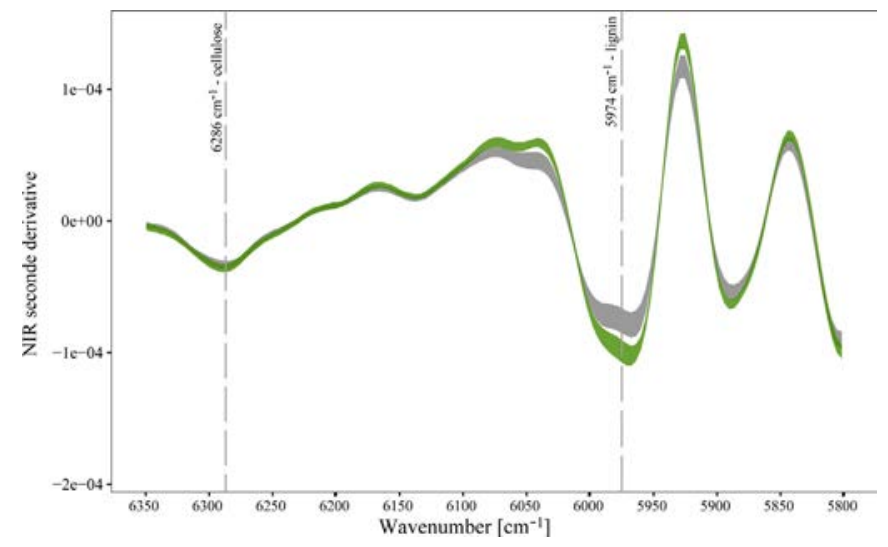

Fig. 9. SD of second derivative spectra of intact samples (green) and decayed samples (grey). Spectral range: $6350-5800 \mathrm{~cm}^{-1}$. (For interpretation of the references to color in this figure legend, the reader is referred to the web version of the article.)

\subsection{Comparison of the levels of decay assessed by the NIRS-based method and the VRM}

\subsubsection{Indicators $D w_{N I R S}$ and $D w_{E_{1}}$}

The indicator $D w_{\text {NIRS }}$ varied from 0.02 to 0.55 and had a mean value of 0.27 (Fig. 10a). The indicator $D w_{E_{1}}$ varied from 0 to 0.59 and had a mean value of 0.22 (Fig. 10b). No significant difference was observed between the different sites. Nevertheless, $D w_{\text {NIRS }}$ of La Terrasse and $D w_{E_{1}}$ of Ecorchiers Bas were differentiated from other sites by their high variability.

\subsubsection{Comparison of methods using means of classes}

The logs were assessed in the first three decay classes (Fig. 11). The NIRS-based method assessed $39 \%$ of the logs in class 1 and $58 \%$ in class 2 versus $68 \%$ and $29 \%$ for the VRM. Class 3 was assigned 
(a) Indicators $D w_{N I R S}$

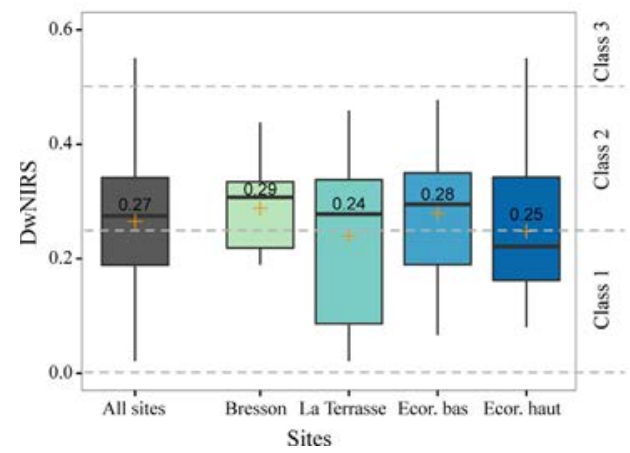

(b) Indicators $D w_{E 1}$

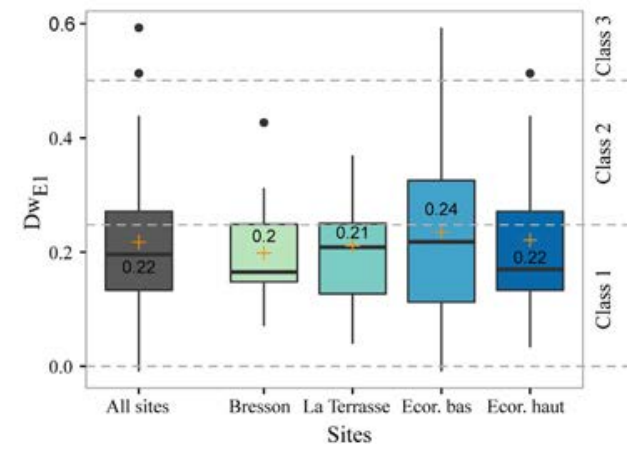

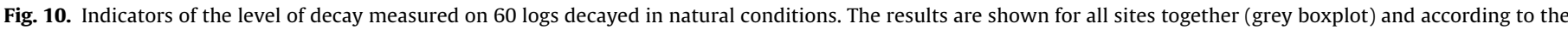
experimental sites. Crosses associated with figures correspond to the mean values of each indicators.

\section{All sites}
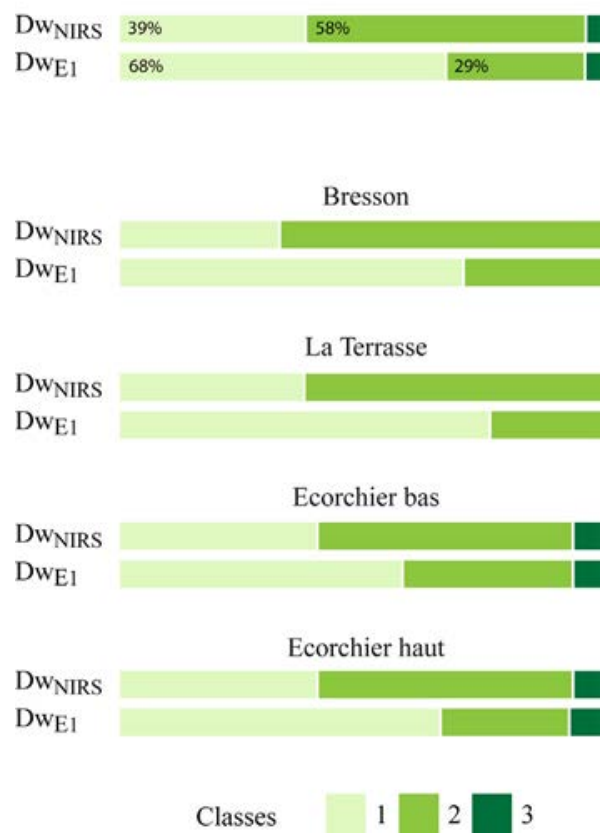

Fig. 11. Comparison of $D w_{E 1}$ and $D w_{N I R S}$ classes of decay.

to two logs by both methods. The comparison of the classifications according to the experimental sites shows the same trend. The VRM assessed logs at class 1 in a higher proportion than the NIRS-based method. Class 3 was assessed in the same sites by both methods (Ecorchiers Haut and Ecorchiers Bas) and in the same proportion. Detailed observation of the class 3 samples shows that it was assessed for the same log in Ecorchiers Haut contrary to Ecorchiers Bas, where it was two different logs. This explains why the agreement between the two methods is $50 \%$ for class 3 (Fig. 12). For other classes, the contingency table shows that the agreement between the two methods is $50 \%$ and $80 \%$ for class 1 and 2 , respectively.

\section{Discussion}

\subsection{Applicability of the methods on samples degraded in natural conditions}

To prevent strong heterogeneity in the cross section and to avoid a side no longer being subject to degradation, both methods were developed from buried samples, contrary to this study where the

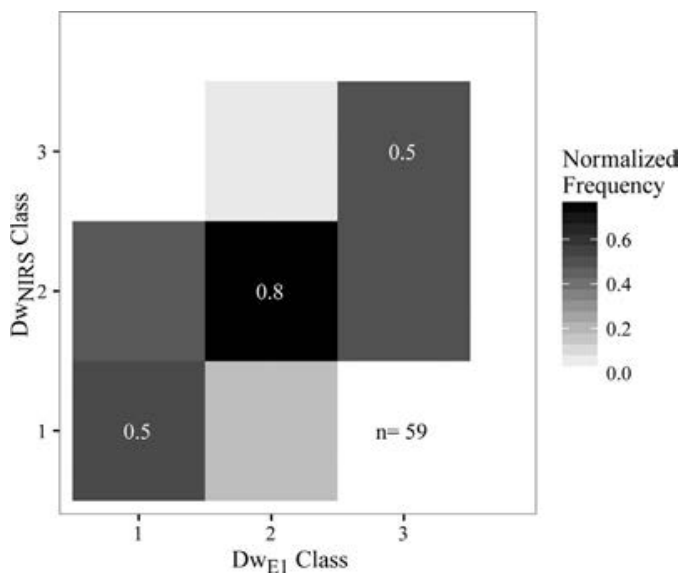

Fig. 12. Contingency table of $D w_{E 1}$ and $D w_{N I R S}$ classes.

samples had a single side in contact with the ground. However, no strong decay heterogeneity was noted in the cross section during visual inspection (Fig. 5).

Prior to VRM measurements, the decayed-sample MC was controlled (Fig. 7). Inter-site MC variations could be the consequence of micro-climatic conditions and differences in soil type. The water-holding capacity varies depending on the soil type and influences the MC of wood in contact with the ground (Rahman and Chattopadhyay, 2007). Surprisingly, intra-site MC variations were considerable. This may partly be explained by the fungal activity given that fungi raise the MC through their mycelia. At the Ecorchier Bas site, where this variation is especially large, it may also be the consequence of the difference in proximity to the torrent. Finally, these moisture conditions were compatible with the requirements of the VRM, which requires a MC above the FSP. Otherwise, the MOE is strongly influenced by the MC and the calculation of the indicator $D w_{E_{1}}$ would be irrelevant.

As wood-boring beetle attacks remained very limited, the changes in mechanical properties were associated with the microbial activity. Moreover, according to the MC and the experimental conditions, the decay occurred in aerobic conditions, which prevents bacterial activity. These conditions were similar to those obtained when developing the NIRS prediction model in semicontrolled conditions (Barré, 2017).

Furthermore, the spectrogram reveals differences in amplitude between the spectra of intact and decayed samples. They were observed for peaks assigned to lignin and cellulose, for example near $5974 \mathrm{~cm}^{-1}$ (lignin) (Fig. 9) and near $4277 \mathrm{~cm}^{-1}$ (cellulose) (Fig. 8). This observation differs from that made by (Barré, 2017). For 
spectra of decayed samples used to develop the prediction model, amplitude changes were essentially observed for bands associated with polysaccharides $\left(4674-4570 \mathrm{~cm}^{-1}, 4404-4350 \mathrm{~cm}^{-1}\right.$, $4304-4258 \mathrm{~cm}^{-1}$ ) (Fig. 8). This difference between the two experiments may be explained by differences in the composition of the microbial community. Therefore, the prediction model needs to be improved to take into account the changes in lignin observed in samples decayed in natural conditions.

\subsection{Comparison of the levels of decay assessed by the NIRS-based method and the VRM}

Both methods classified the levels of decay mainly in the two first classes of all sites (Fig. 11). Over a degradation period of 659 days, they revealed substantial variability in the decay levels, especially for Ecorchiers Haut and Ecorchiers Bas sites. The intra-site variation in levels of decay of structures has already been observed (Rickli and Graf, 2014) and may be explained by several factors. Differences may come from the intra-species variability of the durability observed notably for larch (Curnel et al., 2008). Furthermore, van der Wal et al. (2015) found that the decay rate may be driven by species richness in the fungal community, which potentially varies from one $\log$ to another. The MC at the intact state varied within a broad range from $33 \%$ to $97 \%$ (Fig. 7) and might influence the establishment of fungi. The soil types may also have a large influence on the decay rate (Brischke et al., 2014).

The difference of repartition of classes between both methods may be explained by the spatial characteristics of the measurements. The NIRS-based method is considered as a local measurement as the powder was obtained from a $10 \mathrm{~cm}$ logs sampling. On the contrary, VRM is a global measurement that characterized the whole logs. This may explain a part of the differences observed in the classification results (Fig. 11). However, the systematic predominance of class 1 for each site by VRM compared to NIRS-based method suggests an intrinsic difference in the evaluation of the early stage of decay. The origin of this difference is difficult to determine. However, in the context of assessing the extent of decay of logs used in ecological engineering structures, degraded in natural conditions, we place greater confidence in the assessments obtained by the VRM, which is based on a direct measurement of the MOE, unlike the NIRS method, which depends on the robustness of its prediction model. As seen above, the model used in this study was developed from samples degraded under semi-controlled conditions. These conditions may be too specific to directly develop a model that can be generalized to natural conditions.

These methods can be considered to complement the practitioner's expertise, which generally relies on a qualitative assessment. They do not replace visual inspection, which remains the basis of the appraisal of a structure (Cavalli and Togni, 2013). They are intended to provide quantitative information to the practitioner. However, the use of these methods on real structures requires that the methodologies be adapted. The VRM should be seen as a method dedicated to monitoring the structure starting with its construction. It measures a relative difference of the MOE and requires measurement at the intact state. Furthermore, instead of removing pieces of the structure, which would be similar to a destructive test, we propose to install removable control samples at specific places according to the structure's configuration and its environment. The level of degradation can actually vary to a large extent within a single structure, in particular due to variations in moisture conditions. These control samples may not be structural but may have only a monitoring function to determine the extent of decay. Their characteristics at the intact state might be thoroughly defined and could be freely monitored over time. For that purpose, the in situ test is realistic but the test bench should be improved by exploring measurement feasibility with other supports or other boundary conditions than the free-free condition. As for the NIRS-based method, it may be applied to real structures by assessing decay from cores sampled at critical locations. Cores $5 \mathrm{~mm}$ in diameter do not affect the structural integrity and have already been used in investigating structures (Noetzli et al., 2008). If portable NIRS is considered, this calls for further investigations to quantify the level of decay directly on fresh increment cores.

\section{Conclusion}

In this study, we have tested two methods to assess the level of decay of small-diameter logs initially developed in semi-controlled conditions using the NIRS-based method and the VRM. First, the applicability of the methods was confirmed by means of observations of decay. Different visual indications of decay highlighted the effects of the microbial activity on logs. No strong heterogeneity of decay was observed in their cross sections. It was stated that the fungal community was at least composed by highly active whiterot fungi. The study of NIRS indicates that lignin and cellulose were both affected. In particular, the decreases in amplitude for bands assigned to lignin were pronounced. However, the bands assigned to lignin were not sufficiently taken into account by the prediction model. This may reduce the applicability of the NIRS-based method depending on the rot types involved. Nevertheless, both methods assessed levels of decay in a similar extent. For each site, logs were mainly assessed in the first two classes on a scale of one to four. Class 3 was identified for a few samples on two sites by both methods. The results of the two methods differ, in particular in the higher proportion of class 1 logs assessed by the VRM than those assessed by the NIRS-based method. This may be explained by the difference in the scale investigated, i.e. local for NIRS and global for the VRM. Finally, the use of control samples located at several locations in the structure appraised allows considering both methods for non-destructive evaluation of wooden bioengineering structures.

\section{Acknowledgements}

This work has been funded by Arc Environnement (Rhône Alpes Region, France). We thank ONF and the Isère RTM Department for their support in the experiments.

\section{References}

Akita, H., 2015. Change in the density of old wooden check dams with age: results of an investigation of up to nine-year-old dams in Nagano Prefecture. Nihon Ringakkai Shi/J. Jpn. For. Soc. 97 (2), 127-131.

Barré, J.B., 2017. Assessment of the level of decay of wood in protection structures using NIRS and vibration resonant methods. Ph.D. thesis), Grenoble Alpes University, Grenoble.

Beleites, C., Sergo, V., 2012. hyperSpec: A Package to Handle Hyperspectral Data Sets in R.

Brancheriau, L., Bailleres, H., 2002. Natural vibration analysis of clear wooden beams: a theoretical review. Wood Sci. Technol. 36 (August (4)), 347-365.

Brischke, C., Meyer, L., Olberding, S., 2014. Durability of wood exposed in ground comparative field trials with different soil substrates. Int. Biodeter. Biodegrad. 86 (January (Part B)), 108-114.

Brischke, C., Rapp, A.O., 2008. Influence of wood moisture content and wood temperature on fungal decay in the field: observations in different micro-climates. Wood Sci. Technol. 42 (April (8)), 663.

Cavalli, A., Togni, M., 2013. How to improve the on-site MOE assessment of old timber beams combining NDT and visual strength grading. Nondestruct. Test. Eval. 28 (September (3)), 252-262.

CEN, 2005. EN 1995-1-1. Eurocode 5 - Design of timber structures - Part 1-1 General rules - General rules and rules for buildings. Tech. rep., Brussels, Belgium.

CEN, 2013. EN 335. Durability of wood and wood-based products - use classes: definitions, application to solid wood and wood-based products. Tech. rep. Brussels, Belgium. 
CEN, 2016. EN 350-2. Durability of Wood and Wood-based Products. Natural durability of solid wood. Part 2: Guide to natural durability and treatability of selected wood species of importance in Europe. Tech. rep.

Ceraldi, C., Mormone, V., Russo, E., 2001. Resistographic inspection of ancient timber structures for the evaluation of mechanical characteristics. Mater. Struct. Mater. Construct. 34 (235), 59-64.

Chalmers, J.M., Griffiths, P.R. (Eds.), 2002. Handbook of Vibrational Spectroscopy. J. Wiley, New York.

Curnel, Y., Jacques, D., Gierlinger, N., Pques, L.E., 2008. Variation in the decay resistance of larch to fungi. Ann. For. Sci. 65 (8), 810.

Fackler, K., Schmutzer, M., Manoch, L., Schwanninger, M., Hinterstoisser, B., Ters, T. Messner, K., Gradinger, C., 2007a. Evaluation of the selectivity of white rot isolates using near infrared spectroscopic techniques. Enzyme Microb. Technol. 41 (November (6-7)), 881-887.

Fackler, K., Schwanninger, M., 2012. How spectroscopy and microspectroscopy of degraded wood contribute to understand fungal wood decay. Appl. Microbiol. Biotechnol. 96 (3), 587-599.

Fackler, K., Schwanninger, M., Gradinger, C., Hinterstoisser, B., Messner, K., 2007b. Qualitative and quantitative changes of beech wood degraded by wood-rotting basidiomycetes monitored by Fourier transform infrared spectroscopic methods and multivariate data analysis. FEMS Microbiol. Lett. 271 (2), 162-169.

Feio, A., Machado, J.S., 2015. In-situ assessment of timber structural members: combining information from visual strength grading and NDT/SDT methods - a review. Construct. Build. Mater. 101 (Part 2), 1157-1165.

Kail, J., Hering, D., Muhar, S., Gerhard, M., Preis, S., 2007. The use of large wood in stream restoration: experiences from 50 projects in Germany and Austria. J. Appl. Ecol. 44 (6), 1145-1155.

Kasal, B., Tannert, T. (Eds.), 2011. In Situ Assessment of Structural Timber. Vol. 7 of RILEM State of the Art Reports. Springer, Netherlands, Dordrecht.

Kuhn, M., 2016. caret: Classification and Regression Training.

Maloy, O.C., Murray, T.D. (Eds.), 2001. Encyclopedia of Plant Pathology. Wiley, New York.

Mao, Z., Saint-Andr, L., Genet, M., Mine, F.-X., Jourdan, C., Rey, H., Courbaud, B., Stokes, A., 2012. Engineering ecological protection against landslides in diverse mountain forests: choosing cohesion models. Ecol. Eng. 45, 55-69.

Noetzli, K., Boell, A., Graf, F., Sieber, T., Holdenrieder, O., 2008. Influence of decay fungi, construction characteristics, and environmental conditions on the quality of wooden check-dams. For. Prod. J. 58 (4), 72-79.

Previati, M., Canone, D., Bevilacqua, I., Boetto, G., Pognant, D., Ferraris, S., 2012 Evaluation of wood degradation for timber check dams using time domain reflectometry water content measurements. Ecol. Eng. 44, 259-268.

R Core Team, 2013. R: A Language and Environment for Statistical Computing.

Rahman, A., Chattopadhyay, G., 2007. Soil factors behind inground decay of timbe poles: testing and interpretation of results. IEEE Trans. Power Deliv. 22 (July (3)), 1897-1903

Rey, F., 2009. A strategy for fine sediment retention with bioengineering works in eroded marly catchments in a mountainous Mediterranean climate (Southern ALPS, France). Land Degrad. Dev. 20 (2), 210-216.
Rey, F., 2017. Ecologie ingénieriale: une recherche finalisée au service de l’ ingénierie et du génie écologiques. Revue d' écologie - La Terre et la vie, 72.

Rickli, C., Graf, F., 2014. Timber constructions in torrent control with Norway spruce and silver fir: wood quality and colonisation with decay fungi during the first years. Schweizerische Zeitschrift fur Forstwesen 165 (4), 79-86.

Rinn, F., Schweingruber, F.-H., Schar, E., 1996. RESISTOGRAPH and X-ray density charts of wood comparative evaluation of drill resistance profiles and X-ray density charts of different wood species. Holzforschung 50 (4), 303-311.

Rinnan, S., Berg, F.V.D., Engelsen, S.B., 2009. Review of the most common pre-processing techniques for near-infrared spectra. TrAC Trends Anal. Chem. 28 (November (10)), 1201-1222.

Romano, N., Lignola, G.P., Brigante, M., Bosso, L., Chirico, G.B., 2016. Residual life and degradation assessment of wood elements used in soil bioengineering structures for slope protection. Ecol. Eng. 90, 498-509.

Sandak, A., Ferrari, S., Sandak, J., Allegretti, O., Terziev, N., Riggio, M., 2013. Monitoring of wood decay by near infrared spectroscopy. Adv. Mater. Res. 778 (September), 802-809.

Savitzky, A., Golay, M.J.E., 1964. Smoothing and differentiation of data by simplified least squares procedures. Anal. Chem. 36 (8), 1627-1639.

Schmidt, O., Czeschlik, D., 2006. Wood and Tree Fungi: Biology, Damage, Protection, and Use. Springer, Berlin.

Schwanninger, M., Hinterstoisser, B., Gradinger, C., Messner, K., Fackler, K., 2004 Examination of spruce wood biodegraded by Ceriporiopsis subvermispora using near and mid infrared spectroscopy. J. Near Infrared Spectrosc. 12 (6), 397-409

Schwanninger, M., Rodrigues, J.C., Fackler, K., 2011. A review of band assignments in near infrared spectra of wood and wood components. J. Near Infrared Spectrosc. 19 (5), 287-308.

Signal developers, 2014. Package signal: Signal processing. Tech. rep.

Stokland, J.N., Siitonen, J., Jonsson, B.G., 2012. Biodiversity in Dead Wood. Ecology, Biodiversity, and Conservation. New York, Cambridge University Press.

Tardo, G., Mickovski, S.B., 2016. Implementation of eco-engineering design into existing slope stability design practices. Ecol. Eng. 92, 138-147.

van der Wal, A., Ottosson, E., de Boer, W., 2015. Neglected role of funga community composition in explaining variation in wood decay rates. Ecology 96 (January (1)), 124-133.

Wilcox, W., 1978. Review of literature on the effects of early stages of decay on wood strength. Wood Fiber Sci. 9 (4), 252-257.

Williamson, G.B., Wiemann, M.C., 2010. Measuring wood specific gravity. . .correctly. Am. J. Bot. 97 (3), 519-524.

Zabel, R.A., Morrell, J.J., 1992. Wood Microbiology: Decay and Its Prevention. Academic Press, San Diego.

Zeh, H., 2007. Ingenieurbiologie: Handbuch Bautypen = Gnie biologique = Ingegneria naturalistica $=$ Soil bioengineering $=$ Ingeniera biolgica vdf Hochschulverl, Zrich, oCLC: 180744601. 